\title{
The invisible ophthalmologist
}

\author{
Melanie Hingorani ${ }^{1}$
}

Received: 26 February 2019 / Accepted: 26 February 2019 / Published online: 29 March 2019

(c) The Royal College of Ophthalmologists 2019

Everything feels stretched and under-resourced in the current NHS but ophthalmology is feeling more strain than many specialties, and the significance of this is not well understood outside those delivering ophthalmology care. So much eye disease is linked to older age and diabetes and this, combined with an explosion of diagnostic and treatment options and new requirements for frequent attendances or interventions, is overwhelming ophthalmic services across the UK. Evidence collected via incident reporting, BOSU studies and charities shows nearly 200 patients per year suffering serious visual loss through delayed care and many more suffering lower levels of harm, and the stress and anxiety of knowing they are not being seen on time [1].

Despite College efforts to highlight the issue and push for action, many commissioners, hospital and NHS leaders do not see ophthalmology as a high priority despite the fact that we are now the busiest outpatient specialty and that most of our patients have chronic disorders requiring regular, timely care to prevent disabling sight loss. Diabetes, cancer, cardiovascular disease, mental health, primary care/GPs and A\&E get most of the attention. It's short termism-loss of vision has enormous consequences for people's ability to retain independence, to work and care for themselves and others, it causes falls, psychiatric disease, worsens dementia and is strongly linked with deterioration of other medical disorders. The consequence is a significant impact on national resources with the financial burden of sight loss on the UK economy estimated at $£ 28$ billion [2].

Ophthalmology is taking up the challenge to respond as best it can with current resources, via service transformation for efficiency, greater care delivered by community optometrists, care that was traditionally delivered by doctors being delivered by non-medical staff such as nurses,

Melanie Hingorani

m.hingorani@nhs.net

1 Professional Standards Royal College of Ophthalmologists, London, UK orthoptists, optometrists and technicians, and innovative pathways such as virtual clinics and the beginnings of use of artificial intelligence.

However, the College workforce census provide evidence to support what many already suspected-we will need more doctors for this expansion in care even with all this transformation going ahead at pace [3].

In these difficult times we must optimise and use every available resource to ensure we create capacity to see our patients safely. But there is one human resource we often forget: the SAS doctor, termed by Bhagyashree Shevade the RCOphth SAS Education Lead as "The Invisible Ophthalmologist".

Traditionally, SAS doctors have been the mainstay of ophthalmic services in numerous hospital units and there are more than 650 in the UK currently, compared with just under 1500 consultants [3]. Changes in run through training and availability of locum posts, immigration rules and the closure of the Associate Specialist grade to new applicants have all damaged our ability to recruit and develop SAS doctors.

Most units find it difficult to recruit high quality candidates, and both SAS and consultant ophthalmologists have significant concerns about the future of the position.

Bronwen Attrup's personal career story in this edition of Eye [4] demonstrates how, with the right senior support and understanding of the existing national guidance for SAS doctors' roles, SAS doctors can be lifted from years of low level and unsatisfying service provision to become autonomous clinicians with areas of significant ophthalmic expertise, and even become national leaders within College roles. The RCOphth has identified SAS doctors as a key and valuable group of ophthalmologists who need greater support and engagement to help unlock their full potential and contribute to the desperately required service capacity. The RCOphth undertook its first national survey of SAS ophthalmologists in 2017 [5] and, with this and consultation with SAS doctors through the RCOphth SAS Group, we are pursuing a range of actions to highlight support and guidance already available, change perceptions to see the 
positive aspects of the role, and to motivate, support and optimise SAS clinical and non-clinical contributions.

However, it is incumbent upon consultant ophthalmologists, clinical leads and managers, as well as SAS doctors themselves, to be familiar with national guidance for SAS doctors, to understand these doctors' rights and their responsibilities, and to ensure their requirements for professional development are respected [6-10].

\section{Compliance with ethical standards}

Conflict of interest The authors declare that they have no conflict of interest.

Publisher's note: Springer Nature remains neutral with regard to jurisdictional claims in published maps and institutional affiliations.

\section{References}

1. BOSU report shows patients losing sight to follow-up appointment delays. RCOphth 2017. https://www.rcophth.ac.uk/2017/02/ bosu-report-shows-patients-coming-to-harm-due-to-delays-in-trea tment-and-follow-up-appointments/.

2. Pezzullo L, Streatfield J, Simkiss P, Shickle D. The economic impact of sight loss and blindness in the UK adult population. BMC Health Serv Res. 2018;18:63.

3. Royal College of Ophthalmologists workforce census 2018. https://rcophth.ac.uk/publications/workforce-census-2018/.

4. Attrup B. SAS Ophthalmologist: my positive career choice. Eye (Lond). 2019 (This issue).

5. SAS ophthalmologists - supporting a key workforce. RCOphth 2018. https://www.rcophth.ac.uk/publications/sas-survey-2017/.

6. RCOphth guide to SAS autonomous working 2017. https://www. rcophth.ac.uk/wp-content/uploads/2017/08/RCOphth-Guide-tof-a utonomous-working-for-SAS-ophthalmologists.pdf.

7. RCOphth Clinical lead survival guide-SAS doctors 2017. https://www.rcophth.ac.uk/wp-content/uploads/2018/05/ClinicalLeads-Survival-Guide-Specialty-and-Associate-Specialist-SASDoctors.pdf.

8. BMA Guidance template for the development of autonomous practice for SAS doctors and dentists. BMA. 2015.

9. The BMA SAS charters. https://www.bma.org.uk/advice/ employment/contracts/sas-contracts/sas-charters.

10. AoRMC SAS doctor development guide 2017. http://www.aomrc. org.uk/reports-guidance/sas-doctor-development-guide/. 